\title{
Understanding the Knowledge and Practices of Patent Medicine Vendors towards Tuberculosis Control in a Semi-Urban Area of South-South, Nigeria
}

\author{
Ojule IN ${ }^{1}$, Nwaike $\mathrm{CM}^{2}$, Kingian BE ${ }^{2}$ \\ ${ }^{1}$ Department of Preventive and Social Medicine, Faculty of Clinical Sciences, University of Port Harcourt, Nigeria \\ ${ }^{2}$ University of Port Harcourt Teaching Hospital, Port Harcourt, Nigeria
}

Corresponding author: Ojule I. N; inumanye.ojule@uniport.edu.ng

Received 15 May 2020;

Accepted 16 June 2020;

Published 01 July 2020

\begin{abstract}
Background: Tuberculosis (TB) is a significant health and economic burden in our environment and consistently ranks amongst the most common disease that affects individuals whose immunity has been compromised. It is also one of the major infectious diseases that affect those living with HIV and AIDS. Patent Medicine Vendors (PMVs) are ubiquitous in our Communities and are highly patronized by the populace. This is because they are at close proximity, affordable and accessible to many underprivileged and underserved people in Low and middle income countries. Inadequate knowledge and practice among PMVs will increase morbidity, mortality and promote spread of TB and emergence of Multi-drug resistant strains of TB. The study therefore aimed to understand the knowledge and practices of PMVs towards TB control to enable appropriate intervention. Method: The study was of a descriptive cross-sectional design. Semi-structured self-administered questionnaires in English were administered to forty 'in-charge' Patent medicine vendors to obtain quantitative data on their socio-demographics, their

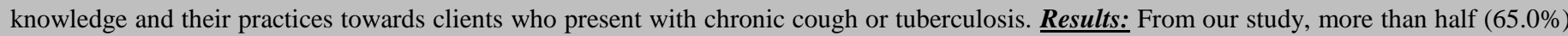
of the respondents identified prolonged cough -lasting more than 2 weeks and bloody cough (75.0\%) as symptoms of TB. Only $27.5 \%$ of the PMVs have heard of DOTS (Directly Observed Treatment Short-course). Only 20.0\% of the PMVs were aware that TB treatment required a minimum of 4 different drugs while $60.0 \%$ of them knew that drug treatment of TB should last for a minimum of 6 months. The majority $(80.0 \%)$ of the PMVs correctly answered that TB drugs in government hospitals are free. When asked the most important tests to request for a client with chronic cough, all (100\%) the PMVs mentioned sputum test and X-ray. The result shows that most of the respondents had good practice on the management of tuberculosis because they tended to refer clients with chronic cough or confirmed cases of TB to the government hospital. In our study, level of education of the PMVs was significantly associated with good practice of TB management, $\mathrm{p}=0.005$. Conclusion: From our study, we understood that the level of knowledge and practices of TB management among PMVs in Alakahia Community is fairly adequate as we assessed them based on knowledge appropriate for them. A lot more still need to be done in area of training and retraining of PMVs on knowledge and practices, as well as educating the public on proper health-seeking behavior.
\end{abstract}

Keywords: Knowledge, Practice, Tuberculosis, Patent Medicine Vendors.

\section{Introduction}

In many low and middle income countries (LMIC) like Nigeria, access to quality healthcare services for a large proportion of the people, especially the under-privileged citizens, is highly limited. In searching for a solution, the United Nations and the WHO consensus recommendation is that Universal Health Coverage (UHC) unequivocally is the global answer to disparities in health indices and care access. In furtherance to that, in 2015 UHC was included as one of the targets of the third Goal of the Sustainable Development agenda with the sole aim of encouraging countries to provide access to quality, essential health services inclusive of safe, effective and affordable medicines for treatment of common diseases and ailments ${ }^{[1,2]}$.
In Nigeria, the reasons for the poor access to healthcare services are multi-factorial. It includes poor political will and commitment as the annual budget and fiscal releases for the health sector year 2020 was only $4.4 \%$ of the National Budget. Others are lack of effective health care safety nets, ignorance, poor educational attainment and very weak national health systems ${ }^{[3]}$.

In many countries in Africa, access to healthcare could be obtained from public health facilities, for-profit private health facilities, not-for-profit private sector health facilities (e.g. NGOs) and lastly, from informal healthcare providers who are mostly medically unqualified. These informal providers include Traditional Birth Attendants, Patent Medicine Vendors and other traditional healers ${ }^{[4]}$.

Majority of Nigerians, especially the low income earners and those living in the rural communities, have little choice other 
than to receive care from this informal sector. The informal sector is popular because they are usually situated right in the middle of where people live and work, they are culturally acceptable, less intimidating, payment for services are negotiable and could be in installments. On the other hand, public health facilities are far from home, hours of service operations limited in some cases, costs and payments not negotiable, drug stock-outs and attitude of health care workers. In the private for-profit facilities costs are astronomical and out of the league of many. These are some of the factors driving the people towards the informal health sector ${ }^{[5,6,7]}$.

The public healthcare facilities are usually well staffed with highly trained manpower including pharmacists. Their services are heavily subsidized, especially for out-patient utilizations, but are grossly inadequate and still unaffordable for the huge poor and under-privileged population of these countries.

In order to provide access to quality health care without financial hardship, global health authorities have advocated the use of health insurance schemes ${ }^{[3]}$. Unfortunately, the existing health insurance schemes in Nigeria (both public and private) is still developing and have had very sparse coverage of less than $10 \%$ of the population ${ }^{[8]}$. The reality on ground therefore is that the vast majority of the people have no health insurance coverage thereby depending on out-of-pocket expenditure to take care of their health care needs. In doing so, they resort to the cheaper, more accessible options, such as the patent medicine vendors and traditional healers [9].

Patent Medicine Vendors are commercial retailers of drugs in the informal private sector. They are known by a variety of names including medicine sellers, drug sellers, chemical sellers, chemists and patent medicine vendors (PMVs). They operate in general shops, market stalls and as itinerant hawkers ${ }^{[10]}$. They are licensed by the Pharmacist Council of Nigeria to stock and sell simple medicinal remedies. The pharmacy law of Nigeria stipulates that PMVs should sell only pre-packaged patent medicines, without splitting the pack. Patent medicines are over-the-counter drugs (OTC) or non-prescription medicines commonly used as household medicaments. They should be oral or external preparations in unit pack used only for a brief medical intervention. These outlets are not permitted to stock prescription-only medicines (POM), only over-the-counter (OTC) products which include cough syrups, pain killers and some anti-malaria. They are not permitted to diagnose diseases. Many however operate outside the guideline in that when a customer approaches them with complaint of ill health or symptoms of an illness. They may or may not ask questions and go on to package drugs for the individual. The common practice is what is called "mixing drugs" whereby the vendor gives a variety of drugs sometimes inside a single envelop ${ }^{[9,10,11]}$.

The basic requirement by law to be licensed as a patent medicine vendor is the ability to read and write in English language, a minimum of primary school education, good character and good standing in the community they operate in. The Pharmacist Council usually conducts orientation training for new patent medicine vendors. This training serves to educate the vendor on his role in the healthcare delivery system, and the ethics and guidelines governing the selling of patent medicines in Nigeria. Many PMVs have attended seminars or workshops organized by stakeholders such as the National Agency for Food, Drug Administration and Control (NAFDAC), National Drug Law Enforcement Agency (NDLEA), non-governmental organizations, and other health care stakeholders ${ }^{[9,12]}$.

Tuberculosis was the leading cause of death from a single infectious pathogen in 2016. TB occurs in every part of the world. In 2017, the largest number of new TB cases occurred in the South-
East Asia and Western Pacific regions, with 62\% of new cases, followed by the African region, with $25 \%$ of new cases.

In $2017,87 \%$ of new TB cases occurred in the 30 high TB burden countries. Eight countries accounted for two thirds of the new TB cases: India, China, Indonesia, the Philippines, Pakistan, Nigeria, Bangladesh and South Africa ${ }^{[13]}$.

The World Health Organization (WHO) Tuberculosis Global Report for 2019, states that tuberculosis (TB) remains a major cause of ill health and is one of the top 10 causes of death worldwide.

TB affects people of both sexes in all age groups but the highest burden is in adult men, who accounted for $57 \%$ of all TB cases in 2018. By comparison, adult women accounted for $32 \%$ and children for $11 \%$. Among all TB cases, $8.6 \%$ were people living with HIV. Most of the morbidity and mortality occur in high burden countries like Nigeria ${ }^{[13]}$.

Let us recall that coughing is a reflex to irritation in the respiratory tract, which is a common phenomenon as long as we draw air into our lungs during respiration. With this, most people view coughing as a natural act thereby failing to recognize when it is a symptom of a more serious illness such as TB. As a consequence of this prevailing scenario, it would not be out of place to assume that majority of poor under-privileged patients with chronic cough would present first to patent medicine vendors (PMVs) for cough remedies. Ukwaja et al reported that $79 \%$ of people with chronic cough reported first to PMVs and pharmacies ${ }^{[14]}$. Since these PMVs play the role of informal first line health workers, this study was therefore designed to understand their knowledge and practices as regards to management of chronic cough such as TB, which is of enormous burden in our country.

The aim of the study was to assess the level of knowledge of tuberculosis and the self-reported practices of PMVs in the management of tuberculosis.

\section{Research method and Design}

\section{Study Area}

The population of Rivers State according to the 2006 census figures is $5,185,400$, which makes it the sixth-most populated state in Nigeria. Alakahia is a semi-urban community in Obio/Akpor Local Government Area, one of the two local government areas that make up Port Harcourt metropolis which is the capital of the state ${ }^{[15]}$. Alakahia is situated on the west side of Port Harcourt metropolis, so well sited in that it is opposite a tertiary health facility and close to a tertiary educational institution.

\section{Study Design}

The study was of a descriptive cross-sectional design conducted in Rivers State, in South-South Nigeria. Primary data was collected for this study.

\section{Study Population}

All Patent Medicine Vendors (PMVs) who sell drugs in Alakahia were recruited. Mobile vendors who hawk patent medicines in and out of Alakahia were excluded. It was a total population study as we took a census of all the PMVs in Alakahia after obtaining their addresses from the zonal Chairman.

\section{Study Procedure}

Semi-structured self-administered questionnaires in English language were administered to the 'in-charge' Patent medicine vendors or a representative to obtain information on their sociodemographics, knowledge of tuberculosis, as well as knowledge of diagnostic and treatment protocol for TB management and their 
practices regarding clients who present with chronic cough such as TB. We wrote a letter to the Zonal Chairman of the association National Association of Patent and Proprietary Medicine Dealers (NAPPMED). After the letter, an interview with their zonal chairman took place. The Chairman read through our questionnaire and asked us questions. We clarified all the details in the questionnaire before he certified our questionnaire as being acceptable to the union.

Four medical students were recruited and trained by the researchers to administer the questionnaire to patent medicine vendors on a 'wait and get' basis in that the research assistants waited while the questionnaires were being filled. The questionnaire was pre-tested on five patent medicine vendors at Choba, a nearby semi-urban area of Port Harcourt, similar to the study site in terms of socio-economic characteristics of the population.

\section{Ethical Considerations}

For Ethical considerations, ethical clearance was obtained from the University of Port Harcourt and written approval was received from the Zonal Chairman of NAPPMED. .

The respondents were assured that their participation will be treated with utmost confidentiality and names/addresses were not collected. Only serial numbers were used.

Informed consent forms were given to each vendor to read and accept before voluntarily filling the questionnaires. It was stated in the informed consent form that the information gathered will be used for research purposes only.

\section{Data Analysis}

Level of Knowledge of Pulmonary Tuberculosis was graded on a 24 point scale. Eight questions were asked and the maximum attainable score was 24 . Responses to the variable were scored with 3 marks assigned to greater or equal to $70.0 \%$ correct answers of PMV and categorized as very good. 50.0\%-69.9\% of correct answers were assigned 2 points and was categorized as good while scores less than $50 \%$ were termed poor. For the assessment of Level of Practice, 6 point scale was used. Responses to the variables were scored with 2 marks assigned to greater or equal to $50.0 \%$ correct answers were categorized as good practice. While one mark was assigned to less than $50.0 \%$ correct answer. Scores $50 \%$ and less were termed poor practice.

Data was entered directly into Microsoft excel 2013 sheets. The data was checked for accuracy and completeness and then subsequently opened and analyzed using IBM SPSS statistics (statistical package for the social sciences) application version 20 for windows operating system owned by IBM SPSS Statistics; as acquired on 31st October 2015 by UNICOM Systems Inc., a division of UNICOM Global, under the UNICOM Intelligence brand.

\section{Data Analysis}

Data was summarized using descriptive statistics such as frequencies, proportions and means for all important variables in the data set. Mean and standard deviation were used for continuous variable and percentages for categorical variables. The demographic variables were cross-tabulated with other variables such as knowledge and practice variables, to see if there were associations. These associations were tested using the chi-squared test, with p-values of $<0.05$ considered statistically significant, and when the value of the variable was less than 5, the Fisher's exact test was applied.

Study Limitation
Like every study, a possible limitation of this survey is information bias due to self reports by respondents. There is need therefore to conduct further research at the community level using mixed qualitative and quantitative methods to gain better insights into the activities of PMVs in our locality. Our study area was purposely selected and that conveys some difficulty in generalizing our results to the whole of Rivers State. As only one community was used, the study results are not representative of what obtains in the whole of Rivers State but may be more relevant in settings similar to Alakahia. It is also anticipated that the study results will have relevance more broadly, specifically in generating hypotheses.

\section{Results}

Table 1: Socio-Demographic characteristics of respondents

\begin{tabular}{|c|c|c|}
\hline Variable & $\begin{array}{l}\text { Frequency } \\
(N=40)\end{array}$ & $\begin{array}{c}\text { Percentage } \\
(\%)\end{array}$ \\
\hline Sex & & \\
\hline Male & 13 & 32.5 \\
\hline Female & 27 & 67.5 \\
\hline Age(years) & & \\
\hline$<20$ & 2 & 5.0 \\
\hline $20-24$ & 2 & 5.0 \\
\hline $25-29$ & 8 & 20.0 \\
\hline $30-34$ & 7 & 17.5 \\
\hline $35-39$ & 7 & 17.5 \\
\hline $40-44$ & 8 & 20.0 \\
\hline $45-50$ & 3 & 7.5 \\
\hline $50-54$ & 1 & 2.5 \\
\hline $55-60$ & 0 & 0.0 \\
\hline$>60$ & 2 & 5.0 \\
\hline $\begin{array}{l}\text { Level of Education } \\
\text { completed }\end{array}$ & Mean $=34.1 \pm 2.7$ years & \\
\hline Tertiary & 13 & 32.5 \\
\hline Senior Secondary & 22 & 55.0 \\
\hline Primary & 2 & 5.0 \\
\hline No Formal Education & 3 & 7.5 \\
\hline
\end{tabular}

Table 1: shows that majority of respondents were female $(67.5 \%)$. The age range was between 16 to 67 years. Mean age was $34.1 \pm$ 2.7 years. About $75 \%$ of respondents were within the age range of $25-39$ years. We noted that the majority of respondents were well educated, as about a third had completed tertiary level of education with more than half at secondary level $(55.0 \%)$. Only $7.5 \%$ of respondents however, self-reported to have had no formal education.

Table 2: Knowledge of tuberculosis

\begin{tabular}{|l|c|c|}
\hline Variable & $\begin{array}{c}\text { Frequency } \\
\text { (N=40) }\end{array}$ & $\begin{array}{c}\text { Percentage } \\
(\%)\end{array}$ \\
\hline Attended TB seminar & 12 & 30.0 \\
Yes & 28 & 70.0 \\
No & & \\
\hline Seen patient with hospital \\
confirmed tuberculosis & 29 & 72.5 \\
Yes & & \\
Known symptoms of & & \\
Tuberculosis: & & \\
Prolonged cough (>2 weeks) & 28 & 65.0 \\
Yes & & \\
Bloody cough & 30 & 75.0 \\
Yes & & \\
\hline
\end{tabular}




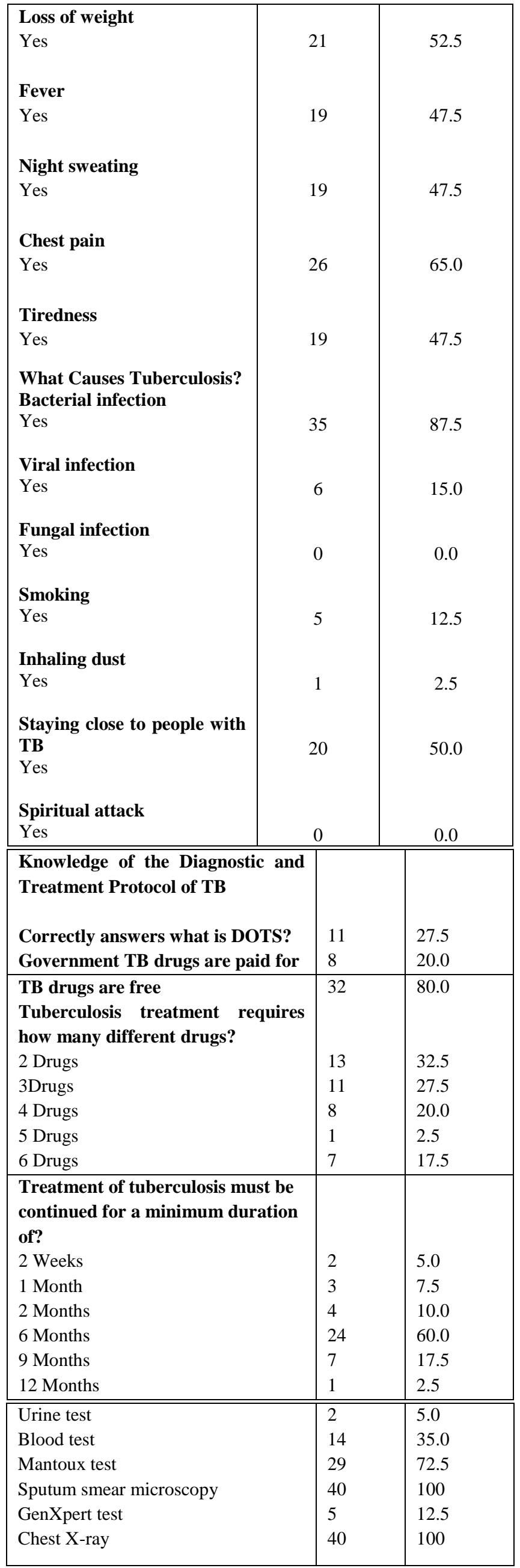

Table 2: shows that only $30.0 \%$ of respondents had attended a seminar on TB. Majority (72.5\%) reported that they had previously attended to a hospital confirmed case of TB. Most of the respondents identified prolonged cough - lasting more than 2 weeks $(65.0 \%)$, and bloody cough $(75.0 \%)$ as symptoms of TB. Most respondents $(87.5 \%)$ were of the opinion that a bacterial organism was the causative agent of TB. Only $25.0 \%$ of respondents however, knew that staying close to people with TB can possibly get one infected with TB.

When a client presented with prolonged cough and requested for treatment, most respondents $(92.5 \%)$ usually give drugs. When a client presented with diagnosed TB and requests treatment, most respondents $(95.0 \%)$ usually referred to the nearby government hospital. Only $5.0 \%$ stated that they usually gave drugs. Only $27.5 \%$ of the PMVs have heard of DOTS (Directly Observed Treatment Short-course). Only $20.0 \%$ of the PMVs were aware that TB treatment required a minimum of 4 different drugs while $60.0 \%$ of them knew that drug treatment of TB should last for a minimum of 6 months. The majority (80.0\%) of the PMVs correctly answered that Government TB drugs are free. When asked the most important tests to request for a client with chronic cough, all the PMVs mentioned sputum test and X-ray.

PMVs practices in management of Tuberculosis

Table 3: Practices in management of tuberculosis

\begin{tabular}{|l|l|l|}
\hline Variable & $\begin{array}{l}\text { Frequency } \\
(\mathbf{N}=\mathbf{4 0})\end{array}$ & $\begin{array}{l}\text { Percentage } \\
(\%)\end{array}$ \\
\hline $\begin{array}{l}\text { What is first done with patient } \\
\text { with prolonged cough who has } \\
\text { requested treatment }\end{array}$ & \\
$\begin{array}{l}\text { No client reported } \\
\text { Give drugs }\end{array}$ & 0 & 0.0 \\
Refer to hospital & 37 & 92.5 \\
Refer for testing & 3 & 7.5 \\
\hline What is done if the above & 0 & 0.0 \\
patient does not get better and & & \\
keeps coming back to you? & & \\
No client reported & 0 & 0.0 \\
Give drugs & 2 & 5.0 \\
Refer to hospital & 38 & 95.0 \\
\hline
\end{tabular}

Have you recommended tests to a client with chronic cough?

Chest X-ray? 2767.5

Sputum test? 3177.5

Mantoux test? 00.0

GenXpert test? 00.0

In further assessment of TB management protocol, $77.5 \%$ and $67.5 \%$ of PMVs have in the past sent their clients for sputum test and chest $\mathrm{X}$-ray respectively.

Table 4: Level of knowledge of the symptoms of tuberculosis

\begin{tabular}{|l|l|l|}
\hline Variable & Frequency(n) & Percentage (\%) \\
\hline Very good knowledge & 16 & 40.0 \\
\hline Good Knowledge & 10 & 25.0 \\
\hline Poor Knowledge & 14 & 35.0 \\
\hline
\end{tabular}

The result shows that $16(40.0 \%)$ of the respondents had very good knowledge of the symptoms of tuberculosis

Table 5: Level of Practice of tuberculosis management

\begin{tabular}{|l|l|l|}
\hline Variable & Frequency (n) & Percent (\%) \\
\hline Good Practice & 38 & 95.0 \\
\hline Poor practice & 2 & 5.0 \\
\hline
\end{tabular}


The result shows that most of the respondents had good practice on the management of tuberculosis because they tended to refer clients with chronic cough or confirmed cases of TB to the government hospital.

Table 6: Relationship between social-demographic characteristics and knowledge of tuberculosis

\begin{tabular}{|c|c|c|c|c|}
\hline Variable & $\begin{array}{l}\text { Very good } \\
\text { n }(\%)\end{array}$ & $\begin{array}{l}\text { Good } \\
\text { n }(\%)\end{array}$ & $\begin{array}{l}\text { Poor } \\
\text { n (\%) }\end{array}$ & $\begin{array}{c}x^{2} \\
\text { (P-Value) }\end{array}$ \\
\hline \multicolumn{5}{|l|}{ Sex } \\
\hline Male & $6(37.5)$ & $3(30.0)$ & $4(28.6)$ & $\begin{array}{l}0.386 \\
(0.913)^{*}\end{array}$ \\
\hline Female & $10(62.5)$ & $7(70.0)$ & $10(71.4)$ & \\
\hline \multicolumn{5}{|l|}{ Age group } \\
\hline$\leq 44$ years & 11(68.8) & $\begin{array}{l}10(100 . \\
0)\end{array}$ & 13(92.9) & $\begin{array}{l}4.697 \\
(0.093)^{*}\end{array}$ \\
\hline$\geq 45$ years & $5(31.3)$ & $0(0)$ & $1(7.1)$ & \\
\hline \multicolumn{5}{|l|}{ Education } \\
\hline Tertiary & $7(43.8)$ & $2(20.0)$ & $4(28.6)$ & $\begin{array}{l}3.572 \\
(0.812)^{*}\end{array}$ \\
\hline Secondary & $8(50.0)$ & $6(60.0)$ & $8(57.1)$ & \\
\hline Primary & $0(0)$ & $1(100)$ & $1(7.1)$ & \\
\hline $\begin{array}{l}\text { No formal } \\
\text { education }\end{array}$ & $1(6.3)$ & $1(10.0)$ & $1(7.1)$ & \\
\hline \multicolumn{5}{|l|}{$\begin{array}{l}\text { TB } \\
\text { Seminar }\end{array}$} \\
\hline Yes & $4(25.0)$ & $2(20.0)$ & $6(42.9)$ & $\begin{array}{l}1.666 \\
(0.502)^{*}\end{array}$ \\
\hline No & $12(75.0)$ & $8(80.0)$ & $8(57.1)$ & \\
\hline
\end{tabular}

*Fisher's exact

Our result shows that there is no statistically significant relationship between socio-demographic characteristics and knowledge of the symptoms of tuberculosis

Table 7: Relationship between socio-demographics and practice of tuberculosis management

\begin{tabular}{|l|l|l|l|}
\hline Variable & $\begin{array}{l}\text { Good } \\
\mathrm{n}(\%)\end{array}$ & $\begin{array}{l}\text { Poor } \\
\mathrm{n}(\%)\end{array}$ & $x^{2}(\mathrm{P}-$ Value $)$ \\
\hline Sex & & & \\
\hline Male & $11(28.9)$ & $2(100)$ & $4.372(0.100)^{*}$ \\
\hline Female & $27(71.1)$ & $0(0)$ & \\
\hline Age group & & & \\
\hline$\leq 44$ years & $32(84.2)$ & $2(100)$ & $0.372(1.000)^{*}$ \\
\hline$\geq 45$ years & $6(15.8)$ & $0(0)$ & \\
\hline & & & \\
\hline Education & & & $10.990(0.005)^{*}$ \\
\hline Tertiary & $13(34.2)$ & $0(0)$ & \\
\hline Secondary & $22(57.9)$ & $0(0)$ & \\
\hline Primary & $2(5.3)$ & $0(0)$ & \\
\hline $\begin{array}{l}\text { No formal } \\
\text { education }\end{array}$ & $1(2.6)$ & $2(100)$ & \\
\hline & & & \\
\hline TB Seminar & & & \\
\hline Yes & $12(31.6)$ & $0(0)$ & $0.902(0.569)^{*}$ \\
\hline No & $26(68.4)$ & $2(100)$ & \\
\hline
\end{tabular}

*Fisher's exact
The result shows that level of education was significantly associated with good practice of tuberculosis management, $\mathrm{p}=0.005$

Table 8: Relationship between knowledge of the symptoms of tuberculosis and management of tuberculosis

\begin{tabular}{|l|l|l|l|}
\hline Variable & $\begin{array}{l}\text { Good } \\
\mathbf{n}(\boldsymbol{\%})\end{array}$ & $\begin{array}{l}\text { Poor } \\
\mathbf{n}(\boldsymbol{\%})\end{array}$ & $\boldsymbol{x}^{\mathbf{2}}$ (P-Value) \\
\hline Knowledge & & & \\
\hline Very good & $15(39.5)$ & $1(50.0)$ & $\begin{array}{l}1.562 \\
(0.713)^{*}\end{array}$ \\
\hline Good & $9(23.7)$ & $1(50.0)$ & \\
\hline Poor & $14(36.8)$ & $0(0.0)$ & \\
\hline
\end{tabular}

*Fisher's exact

There was no significant relationship between knowledge of the symptoms of tuberculosis and practice of tuberculosis management.

\section{Discussion}

Patent Medicine Vendors (PMVs) play important role in the provision of health care to many people in Nigeria particularly in the semi-urban, rural areas and hard to reach areas.

In many instances, PMVs are the only contact of the people with modern health care system. Since this situation is likely not to improve for some time, giving our inability to develop a Universal Health Coverage, there is need therefore to assess how much the PMVs know and what their practices are towards management of Tuberculosis, a foremost cause of morbidity and mortality in our country. In carrying out this study, our hope is that the PMVs will become aware that their activities are being watched and assessed and therefore will be motivated to imbibe good practices.

In assessing how much the PMVs know about TB, it is worthy to note that these frontline informal healthcare providers are not likely to be so very much medically trained. Therefore, our evaluation should be such that is appropriate for their cadre as PMVs. TB knowledge required by PMVs includes the ability to recognize symptoms, identify causes, identify transmission routes and basic knowledge of treatment modality and availability ${ }^{[16]}$.

Nigeria is one of the high burden countries for TB with equally high prevalence of HIV/AIDS amongst the populace13. It is therefore expected that the medicine vendors would have the ability of recognizing the symptoms of these diseases. From our study it was observed that a large percentage of the PMVs in Alakahia community have a fair to good knowledge of Tuberculosis, its signs and symptoms, duration of treatment. This result conforms to results of other studies which have noted that knowledge of health problems is usually high even among the populace, wherever the disease is endemic ${ }^{[17,18]}$.

This good level of knowledge could be due to the location of the community in that it is located in close proximity to a tertiary health institution that has a DOTS clinic and also a tertiary educational institution. The benefit of this close proximity is that the community is a major beneficial of numerous and frequent health programs and surveys emanating from the teaching hospital. Furthermore, its location makes it inhabited by all and sundry so that it is common for the staff of the tertiary institutions to live there and also own such businesses as patent medicine stores.

However, most PMVs did not accurately give the number of months to treat $\mathrm{TB}$ patients.

About $65 \%$ of PMVs correctly mentioned cough of more than 2 weeks, bloody cough, weight loss, chest pain as symptoms of TB. 
Understandably, tiredness, night sweats and fever were mentioned by less than $50 \%$ of the PMVs.

This shows high level of knowledge of TB symptoms. A review report noted that many PMVs had better knowledge of causes of illnesses, signs and symptoms but poor knowledge of correct treatment guidelines and protocol19. The correct cause of Tuberculosis was reported in greater proportion of the PMVs.

$87.5 \%$ were able to correctly mention that $\mathrm{TB}$ was a bacterial infection, while $50 \%$ agreed TB could be contracted by staying close to someone with the Chronic Cough. In a related survey also in southern Nigeria, Olakunle et al reported that $57.9 \%$ of PMVs in their study had good knowledge appropriate for PMVs. In that same study, $93.7 \%$ knew TB was a bacterial disease and $67.9 \%$ reported that TB could be spread by air borne ${ }^{[20]}$.

Evaluation of the knowledge of Diagnostic and treatment protocol showed only $37.5 \%$ knew the correct meaning of DOTS. This was not surprising. A common knowledge is that where TB is treated is usually referred to as Chest or TB clinic and not DOTS clinic.

Knowledge of the number of drugs was poor as the best response was $32.5 \%$ which mentioned two drugs for effective treatment of TB. This result is similar to the South-West Nigeria report whereby $99.4 \%$ of PMVs assessed did not know the names of anti-TB drugs. The lack of knowledge of anti-TB drugs should be viewed as a good thing in the sense that it will lead to less improper prescription and more referral to the hospital. A possible explanation is that we know that the most popular and effective drugs for TB are two (INH and Rifampicin). However in Nigeria, the recommendation by NTBLCP is 4-drug fixed combination regimen ${ }^{[21]}$. It was good to note that $80 \%$ of PMVs knew TB drugs at government hospital are free.

There was adequate knowledge of duration of treatment, as more than $60 \%$ responded that treatment should be continuous for at least 6 months. All the PMVs in our study were able to correctly identify sputum test and chest radiograph as the most important tests for a patient with TB. We would have been surprised if the GenXpert test was among the most important tests mentioned by the PMVs because this is the newest test in TB diagnostics and many private sector health care providers are not conversant with its use. Moreover, in Nigeria at the moment its services are only provided under the National TB program.

The practices of patent medicine vendors are of concern as they are a widely patronized source of drugs for the home management of various common health conditions. So in assessing their practice towards management of $\mathrm{TB}$, we asked what is done for a client that presents with chronic cough, some reported they give drugs, while smaller proportion will refer for testing. Only $7.5 \%$ will refer to the hospital at initial contact. For a client that presents with cough unresponsive to initial treatment, $75.0 \%$ mentioned that they will refer to the government hospital nearby. It appears that the desired practice of referring a patient who continues to present with cough was good. The PMVs hardly refer chronic cough at first contact until they have administered some treatment. The reasoning is that first, they are in business to make money. Second, the clients came to them for help so there is need to offer some remedy first with the hope that will ameliorate the problem. Thirdly, coughing is a common and natural activity mediated by an involuntary reflex. We also know that most people have several episodes of cough yearly that do not turn out to be TB. Several of these episodes are managed at the community level or abort naturally due to herd immunity. The implication of the delay in referral of a case of $\mathrm{TB}$ is that the client continues to infect others. Also inappropriate use of anti-TB medication can predispose to drug resistant Tuberculosis ${ }^{[22,23]}$.

Our study showed no statistically significant association between socio-demographic characteristics and knowledge of the symptoms of tuberculosis although we noted that higher level of education was significantly associated with good practice of tuberculosis management. This result is corroborated by a 2016 research on Drug Vendors in Nigeria. They found that many PMVs were medically trained or shop owners are medically trained (as medical doctors, nurses, midwives, or as community health extension workers). They further noted that with some training and oversight, activities of PMVs may improve access of a large population to basic healthcare services ${ }^{[9,12,13]}$.

\section{Conclusion}

The End TB Strategy includes targets of a $90 \%$ reduction in TB deaths and $80 \%$ in TB incidence rate (new and relapse cases per 100000 population per year) between 2015 and 2030. The 2020 milestone of a $35 \%$ reduction in TB deaths and a $20 \%$ reduction in $\mathrm{TB}$ incidence rates is here. It is therefore of essence that we undertake studies like this to understand what ubiquitous informal providers such as the PMVs know and their practices towards TB management.

From our study, the level of knowledge and practices of Tuberculosis management among PMVs in Alakahia Community is fairly adequate as we assessed them based on knowledge appropriate for them. A lot more still needs to be done in area of training and retraining of PMVs on knowledge and practices, as well as educating the public on proper health-seeking behavior. These will enhance early detection, improve management and reduce complications of Tuberculosis. Some researchers have argued that if properly trained and armed with better knowledge, the PMVs can be quite effective. In our present circumstance, it may be a good method of increasing access to health services. In the absence of NHIS, PMVs have come to play a critical role in healthcare provision. Therefore, it is necessary to recognize and train them in other to expand their already substantial role in supporting the Nigerian health sector.

\section{Recommendation}

As earlier stated, PMVs are ubiquitous in the country and serve as the first port of call for many seeking health services. We, therefore, recommend the following for their optimal health service delivery.

1. Proper educational interventions to improve knowledge and ensure better practices that are in line with the expected knowledge and practice in Tuberculosis management among PMVs should be ensured. They should be engaged by the National Tuberculosis and Leprosy Control Program (NTBLCP).

2. Pharmacy Council of Nigeria (PCN) should ensure that there are regulatory controls on the kind of medications that are at the disposal of PMVs to dispense (most especially antibiotics) as abuse of these medications result in resistance to anti-microbial drugs.

3. Government at all levels under the ministry of health should organize relevant workshops and make attendance compulsory for renewal of license for all PMVs. 
4. Community-based health education programs should be put in place to encourage appropriate health-seeking behaviour among the populace.

\section{Financial Support and Sponsorship}

The study was self-funded.

\section{Conflict of Interest}

None declared.

\section{Authors' contribution}

NCM, KBE designed the study, conducted the literature search and wrote up the initial work. OIN designed the study, general supervision and wrote up the manuscript. All read through and approved the manuscript.

\section{References}

[1] World Health Organization. The world health report: health systems financing: the path to universal coverage: executive summary. World Health Organization; 2010.

[2] United Nations, Sustainable Development Goals [Internet]. Sustain. Dev. Goals 17 Goals to Transform ourWorld, 2015 , http://www.un.org/sustainabledevelopment/sustainabledevelopment-goals/.

[3] Riman HB, Akpan ES. Healthcare financing and health outcomes in Nigeria: A state level study using multivariate analysis. International Journal of Humanities and Social Science. 2012; 2(15), 296-309.

[4] Joarder T, Chaudhury TZ, Mannan I. Universal Health Coverage in Bangladesh: activities, challenges, and suggestions. Advances in Public Health. 2019.

[5] Jowett M, Miller NJ. The financial burden of malaria in Tanzania: implications for future government policy. The International Journal of health planning and management. 2005 Jan; 20(1):67-84.

[6] McCombie SC. Treatment seeking for malaria: a review of recent research. Social science \& medicine. 1996; 43(6):933-45.

[7] Williams HA, Jones CO. A critical review of behavioral issues related to malaria control in sub-Saharan Africa:: what contributions have social scientists made? Social science \& medicine. 2004 Aug 1; 59(3):501-23.

[8] Eteng FO, Ijim-Agbor U. Understanding the challenges and prospects of administering the national health insurance scheme in Nigeria. International Journal of Humanities and Social Science Research. 2016;2(8). Pg 43-48.

[9] Brieger WR, Osamor PE, Salami KK, Oladepo O, Otusanya SA. Interactions between patent medicine vendors and customers in urban and rural Nigeria. Health policy and planning. 2004 May 1; 19(3):177-182.
[10] Pharmacists Council of Nigeria. Guidelines on the issuance of Patent and Proprietary Medicines Vendor's License. 2003. 9

[11] Goodman C, Kachur SP, Abdulla S, Bloland P, Mills A. Drug shop regulation and malaria treatment in Tanzania-why do shops break the rules, and does it matter?. Health policy and planning. 2007 Nov 1;22(6):393-403.

[12] Egboh AA. Pharmacy laws and practice in Nigeria. Lantern Books, Division of Literamed Publications; 1984.

[13] Liu J, Prach LM, Treleaven E, Hansen M, Anyanti J, Jagha T, Seaman V, Ajumobi O, Isiguzo C. The role of drug vendors in improving basic health-care services in Nigeria. Bulletin of the World Health Organization. 2016 Apr 1;94(4):267.

[14] World Health Organization (WHO). Global Tuberculosis Report 2019. Geneva: World Health Organization (WHO); 2019.

[15] Ukwaja KN, Alobu I, Nweke CO, Onyenwe EC. Healthcare-seeking behavior, treatment delays and its determinants among pulmonary tuberculosis patients in rural Nigeria: a cross-sectional study. BMC health services research. 2013 Dec 1;13(1):25.

[16] Rivers State Government Website. Available from: http://www.riversstate.gov.ng/. [Last retrieved on 2019 Oct 11 07].

[17] Obi IE, Nwagbo D, Onwasigwe CN. Tuberculosis knowledge, perception and practice among patent medicine vendors in south-east, Nigeria. J Coll Med. 2010 Dec;15:29-36.

[18] Aikins MI, Pickering H, Greenwood BM. Attitudes to malaria, traditional practices and bednets (mosquito nets) as vector control measures: a comparative Study in Five West Africa Countries. J. Trop. Med. Hyg. 1994;97:81-6.

[19] Beyeler N, Liu J, Sieverding M. A systematic review of the role of proprietary and patent medicine vendors in healthcare provision in Nigeria. PLoS One. 2015;10(1).

[20] Olakunle SO, Olanrewaju O, Olarewaju AO, Fasanmi A, Opara UR. Knowledge Gap about Tuberculosis Case Detection among Patent Medicine Vendors in Osogbo: Implications for Social Work. European Journal of Pharmaceutical and Medical Research. 2016;3:89-93.

[21] Adejumo O, Olusoji D, Otesanya A, Salisu-Olatunji S, Abdul-Razzaq H. Evaluation of outcomes of tuberculosis management in private for profit and private-not-forprofit directly observed treatment shortcourse facilities in Lagos state, Nigeria. Niger Med J. 2017;58(1):44-9. 34.

[22] Federal Ministry of Health. National Tuberculosis, Leprosy and Burili Ulcer Management and control Guidelines. 6th ed. Abuja: Federal Ministry of Health, Nigeria. 2015

[23] Gidado M, Ejembi CL. Tuberculosis case management and treatment outcome: assessment of the effectiveness of public-private mix of tuberculosis program in Kaduna state, Nigeria. Ann Afr Med. 2009;8(1):25-31 